\title{
A covalent organic/inorganic hybrid proton exchange polymeric membrane: synthesis and characterization
}

\author{
M. Luisa Di Vona ${ }^{\mathrm{a}, *}$, Debora Marani ${ }^{\mathrm{a}}$, Alessandra D'Epifanio ${ }^{\mathrm{a}}$, Enrico Traversa ${ }^{\mathrm{a}}$, \\ Marcella Trombetta ${ }^{\mathrm{b}}$, Silvia Licoccia ${ }^{\mathrm{a}, * *}$ \\ ${ }^{a}$ Dipartimento di Scienze e Tecnologie Chimiche, Università di Roma Tor Vergata, via della Ricerca Scientifica 1, 00133 Roma, Italy \\ ${ }^{\mathrm{b}}$ C.I.R.-Centro di Ricerca, Università Campus Bio-Medico, via Longoni 83, 00155 Roma, Italy
}

Received 2 August 2004; received in revised form 17 December 2004; accepted 19 December 2004

Available online 11 January 2005

\begin{abstract}
Commercial polyetheretherketone (Victrex PEEK) was sulfonated up to $90 \%$ degree of sulfonation (DS), then reacted with $\mathrm{SiCl}_{4}$ to obtain a hybrid polymer. The product was characterized by ${ }^{29} \mathrm{Si} \mathrm{NMR}$ and ATR/FTIR spectroscopies demonstrating the formation of covalent bonds between the organic and inorganic components. No dispersed inorganic silicon was present in the product as evidenced by the lack of any resonance at $\delta<-100 \mathrm{ppm}$. Despite the high DS the physicochemical properties of the hybrid were suitable for the preparation of membranes exhibiting high and stable conductivity values $\left(10^{-2} \mathrm{~S} / \mathrm{cm}\right)$, hence suitable for application as ion exchange membrane.
\end{abstract}

(C) 2004 Elsevier Ltd. All rights reserved.

Keywords: Organic/inorganic hybrid polymer; Proton exchange membrane; Polyetheretherketone (PEEK)

\section{Introduction}

Polyethereetherketone (Victrex PEEK) is a very well known polymer with low cost, excellent mechanical and thermal properties, and broad chemical resistance, which make it suitable for a variety of applications from the aerospace to the medical and electronic industries. Chemical modifications of such polymer may lead to further innovative applications. Thus, for instance, sulfonation adds proton conductivity as a further feature of PEEK. The conductivity of sulfonated PEEK (SPEEK) is large enough to meet the requirements needed for applications in fuel cells. However, its mechanical properties progressively deteriorate with sulfonation: these membranes show, in fact, strong swelling when the sulfonation degree (DS) is high enough to achieve high proton conductivity [1-4].

Several strategies can be followed to improve the performance of ion conducting membranes based on arylene main-chain polymer. Covalent or physical crosslinking have

\footnotetext{
* Corresponding authors. Tel.: +39067 259 4385; fax: +39067 259 4328. ** Tel.: +39067 259 4386; fax: +39067 2594328 .

E-mail address: divona@uniroma2.it (M.L. Di Vona).
}

been proposed: for instance, crosslinked sulfonated polyphenylethersulfone (PSU) membranes have been prepared by S-alkylation of PSU with dihalogenoalkanes [5] and crosslinking or blends of SPEEK with basic polymers have been reported to show good chemical stability and proton conductivity $[6,7]$.

Another strategy is to prepare composite membranes containing inorganic fillers dispersed in the organic polymer network. The retention of adsorbed water on the filler surface leads to improved performance in this Class I hybrid materials where the two components are held together by weak non-covalent interactions [8-11]. The conduction mechanism of sulfonated polymers is, in fact, water assisted, and thereby their hydration state is a crucial factor for good electrochemical performance [12].

These composites combine organic and inorganic components in a single material leading to very interesting and novel properties. It is, however, hard to achieve homogeneity at molecular level. The control at atomic level of the proper dosage and dispersion of the inorganic component can be reached via the preparation of Class II hybrids, where the organic and inorganic moieties are linked through covalent bonds. The peculiar macroscopic 
properties of hybrid materials derive by the synergic merge at the molecular scale of the component characteristics, leading to their increasing use for a variety of applications $[8,13,14]$.

Two main types of hybrid materials can be individuated: inorganic/organic and organic/inorganic. In the former, organic moieties are bound to an inorganic polymeric matrix, generally polysiloxanes, generating ORganically MOdified SILanes (ORMOSILs). The latter are characterized by a high content of organic networks similar to carbon-based polymers (Organic Inorganic Polymers, OIP). Modulation of the properties of the final materials can be achieved by proper dosage of the inorganic and organic components [15].

ORMOSIL-based ionoconducting species have been reported [16], but no reports have been made, to the best of our knowledge, on OIP for the preparation of ionexchange membranes.

This paper reports on the preparation and characterization of a new hybrid polymer where $\mathrm{Si}$ atoms are covalently bound to the SPEEK backbone.

\section{Experimental section}

\subsection{Materials}

Polyetheretherketone (PEEK) was obtained from Victrex in the form of powder $(450 \mathrm{P}, \mathrm{MW}=38,300)$. Anhydrous THF and DMSO were prepared according to literature procedures [17].

All other chemicals (Aldrich) were reagent grade and were used as received.

\subsubsection{Synthesis of SPEEK: sulfonation of PEEK}

PEEK (20 g, 69 meq) was dissolved in $\mathrm{H}_{2} \mathrm{SO}_{4}(96 \%, 1 \mathrm{~L})$ and stirred at $50{ }^{\circ} \mathrm{C}$ for 5 days. The solution was poured in a large excess of ice-cold water, under continuous stirring obtaining a white precipitate. After standing overnight, the precipitate was filtered and washed several times with cold water to neutral $\mathrm{pH}$. The sulfonated polymer (SPEEK) was then dried under vacuum for $4-6 \mathrm{~h}$ at room temperature. The degree of sulfonation (DS) was evaluated both by ${ }^{1} \mathrm{H}$ NMR and by titration, according to published procedures [18]. Both methods gave according results, indicating a $\mathrm{DS}=$ $90 \%$.

\subsubsection{Synthesis of SiSPEEK: silylation of SPEEK}

The reaction was carried out under nitrogen by dissolving SPEEK (1.5 g, $4.1 \mathrm{meq})$ in 1.3 L of a DMSO/THF 1:25 solution. The resulting solution was cooled to $-60{ }^{\circ} \mathrm{C}$, then an excess of BuLi (2.5 M in hexane, $16.5 \mathrm{~mL}, 41 \mathrm{mmol}$ ) and $\mathrm{N}, \mathrm{N}, \mathrm{N}^{\prime}, \mathrm{N}^{\prime}$-tetramethylethylenediamine (TMEDA, $6.56 \mathrm{~mL}$, $41 \mathrm{mmol}$ ) were added, and the solution was stirred for $8 \mathrm{~h}$ at $-60{ }^{\circ} \mathrm{C} . \mathrm{SiCl}_{4}(0.47 \mathrm{~mL}, 4.1 \mathrm{mmol})$ was then added and the solution was slowly warmed to room temperature, then kept at reflux overnight.

Absolute ethanol $(250 \mathrm{~mL})$ was then added maintaining the mixture at reflux for further $5 \mathrm{~h}$. After cooling to RT, the precipitate formed was left to settle overnight, then filtered and washed with cold water until all no chlorides where present. The product (SiSPEEK) was dried under vacuum for 4 h. El. An.: \% Si=1.3 \pm 0.1 (reproducible over three samples).

\subsection{Preparation of membranes}

SiSPEEK membranes were prepared by solution casting. In a typical procedure, the polymer $(250 \mathrm{mg})$ was dissolved in DMSO $(30 \mathrm{~mL})$ and the solution was stirred for $4 \mathrm{~h}$. The solution was then evaporated to $5 \mathrm{~mL}$, then cast onto a Teflon plate and heated to dryness. After cooling to room temperature, the resulting membranes were peeled off and dried at $120{ }^{\circ} \mathrm{C}$ for $10 \mathrm{~h}$, then further dried under vacuum at $80^{\circ} \mathrm{C}$ for $4 \mathrm{~h}$ to completely remove the solvent. The thickness of the dried membranes was about $400 \mu \mathrm{m}$. The hybrid membranes were activated in $5 \mathrm{M} \mathrm{H}_{2} \mathrm{SO}_{4}$ for $1 \mathrm{~h}$ at room temperature, then rinsed with deionized water.

\subsection{Water uptake}

Activated SiSPEEK membranes were dried in vacuum at $100{ }^{\circ} \mathrm{C}$. Disks with a diameter of $6 \mathrm{~mm}$ and thickness of $400 \mu \mathrm{m}$ were cut from the membranes and weighted. The disks were then soaked in water at room temperature and weighted after blotting with absorbent paper until no further weight gain was observed. The weight gain of absorbed water was calculated referring to the weight of the dry sample: $\left(W_{\text {wet }} / W_{\text {dry }}-1\right) \times 100$.

\subsection{Measurements}

${ }^{1} \mathrm{H},{ }^{13} \mathrm{C}$ and ${ }^{29} \mathrm{Si}$ NMR spectra were recorded with a Bruker Avance 400 spectrometer operating at 400.13, 100.56 and $79.49 \mathrm{MHz}$, respectively. DMSO- $\mathrm{d}_{6}$ was used as solvent for ${ }^{1} \mathrm{H}$ spectra while ${ }^{13} \mathrm{C}$ and ${ }^{29} \mathrm{Si}$ NMR spectra were recorded in DMSO, using $\mathrm{D}_{2} \mathrm{O}$ as external lock and Ernst angle to minimize acquisition time. Chemical shifts (ppm) are referenced to tetramethylsilane (TMS).

Silicon atomic charge was calculated on the optimized geometries obtained by semiempirical methods (AM1) using the Hyperchem program [19]. Geometric optimizations were terminated when the energy difference among successive iteration was lower than $4.18 \times 10^{-3} \mathrm{~kJ} / \mathrm{mol}$. Starting from AM1 geometries, single point ab initio computation were performed using the Gaussian 98 system of programs [20].

Thermogravimetric analyses were carried out using a thermobalance (STA 409, Netzsch) in Ar flow $(80 \mathrm{~mL} / \mathrm{m})$ with a heating rate of $10^{\circ} \mathrm{C} / \mathrm{min}$ in the range $25-800{ }^{\circ} \mathrm{C}$ on samples dried at $100{ }^{\circ} \mathrm{C}$ for $12 \mathrm{~h}$. 
ATR/FTIR spectra were collected in the range 4000$550 \mathrm{~cm}^{-1}$, on a Nicolet 870 E.S.P. with a Golden Gate MK2 Diamond Specac cell. Spectra were recorded positioning the samples on cell platform operating at room temperature (32 scans, $2 \mathrm{~cm}^{-1}$ resolution).

Electrochemical impedance spectroscopy (EIS) measurements were used to evaluate proton conductivity, using a Solartron 1255 coupled with a dielectric interface in the frequency range $100 \mathrm{KHz}-1 \mathrm{~Hz}$ and an oscillating voltage of $10-100 \mathrm{mV}$. The spectra were analyzed using the EQUIVCRT program by Boukamp. The activated and fully hydrated membranes were placed in a test cell, where they were clamped between two platinum electrodes with a permanent pressure. The conductivity $\sigma$ of the samples in the transverse direction was calculated from the impedance data, using the relation $\sigma=d / R S$, where $d$ and $S$ are the thickness and face area of the sample and $R$ was derived from the high frequency intercept with the $\operatorname{Re}(\mathrm{Z})$ axis on a complex impedance plane plot. Values of $d$ and $S$ were determined after the measurements.

\section{Results and discussion}

Aim of this work was to prepare an organic/inorganic hybrid containing sufficient amount of inorganic component to improve SPEEK mechanical properties without significantly alter its conductivity performances. Despite its poor mechanical properties and difficulties in manipulation, it was chosen to use SPEEK with a high degree of sulfonation (90\%) to enhance conductivity, since solubility can be modulated by proper dosage of the inorganic component. To avoid degradation and cross-linking reactions sulfonation was carried out with $96 \% \mathrm{H}_{2} \mathrm{SO}_{4}$ [18].

The first synthetic step in the preparation of the hybrid was to react SPEEK with butyllithium. The reaction was carried out in a mixture of solvents to attain proper solubility of the substrate at low temperature, and in the presence of TMEDA, which is known to promote the aromatic substitution reaction [21]. Subsequent reaction with $\mathrm{SiCl}_{4}$, followed by alcoholysis, lead to the formation of a product which elemental analysis showed the presence of $1.3 \pm 0.1 \% \mathrm{Si}$, corresponding to a ratio $100: 17$ monomeric unit:silicon.

NMR and ATR/FTIR analyses of the products were carried out to verify the formation of a covalent hybrid structure. The ${ }^{29}$ Si NMR spectrum of SiSPEEK (Fig. 1) showed two resonances (relative intensity $4: 1$ ) at -72.5 and $-82.0 \mathrm{ppm}$. The chemical shifts are typical of polyarylsilicon T units [22]. No dispersed inorganic silicon is present, as demonstrated by the lack of any peak at $\delta<-100 \mathrm{ppm}$ where $\mathrm{Q}$ units are expected to resonate [23].

The position of metalation on the polymer backbone is determined by the relative acidity of hydrogens and by the directing effect of substituent groups. Both carbonyl electronic effects and the coordinative ability of sulfonic groups must be considered. If the former are dominant, lithiation will lead to the substituted benzophenonic ring (Scheme 1, product a) while, if the latter prevails, substitution will occur on the ethereal ring leading to product $\mathrm{b}$ (Scheme 1). The presence of two resonances in the ${ }^{29} \mathrm{Si}$ NMR spectrum of the sample indicates the formation of both products. ${ }^{1} \mathrm{H}$ and ${ }^{13} \mathrm{C}$ NMR spectra were of no aid in assigning the structures corresponding to the resonances observed in the ${ }^{29} \mathrm{Si}$ NMR spectrum of SiSPEEK: no evident differences were in fact observed in the spectra of SiSPEEK with respect to the corresponding SPEEK spectra, probably because of the low degree of substitution and to the presence of three different forms: Siunsubstituted units and products a and $\mathrm{b}$, accounting respectively for $83.0,3.5$ and $13.5 \%$ of the total spectral intensity. It is, however, known that, among the different factors affecting chemical shifts, the observed nucleus atomic charge is related to chemical shift, and that, in the case of ${ }^{29} \mathrm{Si}$, electron withdrawing substituents lead to resonances shifted at higher frequency $[23,24]$. Computational calculations of silicon atomic charge were thus carried out on the two monomers corresponding to products $a$ and $b$. Since atomic charges are not quantum mechanical observables and methods for their calculation are necessarily arbitrary, it is not their absolute values that should be considered, but only their variation: the obtained values, 1.669 and 1.715 respectively, allowed to assign the resonance at -72.5 to product a and the one at $-82.0 \mathrm{ppm}$ to product $b$.

The ATR-FTIR spectra of SiSPEEK and SPEEK are shown in Fig. 2a and b, respectively. Nguyen and Ishida reported the transmission FTIR spectra of PEEK films [2527]. The current ATR spectra showed bands at similar frequencies. As the intensities of ATR infrared bands are wavelength-dependent, bands at lower frequencies are more intense than those observed in transmission. Both samples

(a)

(b)

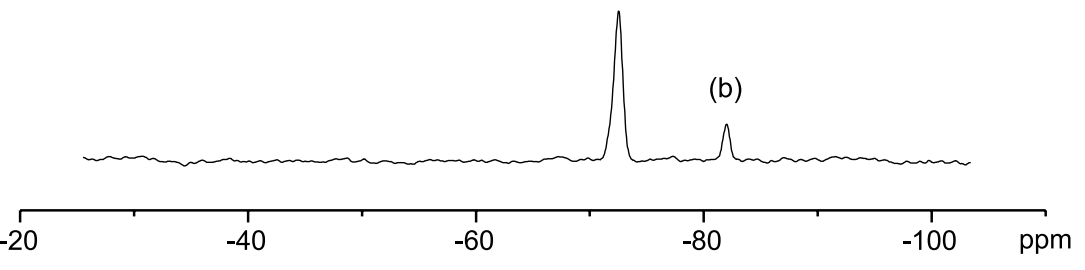

Fig. $1 .{ }^{29} \mathrm{Si}$ NMR spectrum of SiSPEEK. 
<smiles>COc1ccc(Oc2ccc(C(=O)c3ccc(C)cc3)cc2)cc1</smiles>

Scheme 1.

show a series of PEEK characteristic bands: $1600 \mathrm{~cm}^{-1}$ $v_{\mathrm{C}=\mathrm{O}}, 1217 \mathrm{~cm}^{-1} v_{\mathrm{Ph}-\mathrm{CO}-\mathrm{Ph}}, 1025 \mathrm{~cm}^{-1} v_{\mathrm{C}-\mathrm{O}-\mathrm{C}}$ or $v_{\mathrm{C}-\mathrm{O}}$, and $929 \mathrm{~cm}^{-1} v_{\text {sy }} \mathrm{Ph}-(\mathrm{C}=\mathrm{O})-\mathrm{Ph}$. All bands show a shift at lower frequencies, with respect to reference data, due to the presence of the sulfonic group, which is mainly characterized by two bands in the range $1190-1170 \mathrm{~cm}^{-1}$. The antisymmetric and symmetric stretching vibrations of the $\mathrm{SO}_{3} \mathrm{H}$ and $-\mathrm{SO}_{3}^{-}$groups are masked by the strong vibration of $\mathrm{C}-\mathrm{H}$ in-plane-deformation mode of polysubstituted aromatic compounds [28]. However, as shown in Fig. 2c, $v_{\mathrm{as}}\left(\mathrm{SO}_{3}^{-}\right)$and $v_{\mathrm{s}}\left(\mathrm{SO}_{3}^{-}\right)$can be observed at 1196 and $1183 \mathrm{~cm}^{-1}$ in the trace obtained subtracting the spectrum of SPEEK (in its acidic form) from that of SiSPEEK (in anionic form) [28]. The two bands at 933 and $875 \mathrm{~cm}^{-1}$, observed in the subtraction spectrum, are typical of aromatic silanols. A third band at $1127 \mathrm{~cm}^{-1}$ can be attributed to the in-plane deformation of the ring, with some contribution from the $\mathrm{Si}-\mathrm{C}$ stretch [28]. Moreover, a new component of the $v_{\mathrm{C}-\mathrm{O}-\mathrm{C}}$ band appears at $1029 \mathrm{~cm}^{-1}$ indicating a perturbation of the $\mathrm{C}-\mathrm{O}-\mathrm{C}$ bond stretching. A shift $\left(\Delta v \approx 4 \mathrm{~cm}^{-1}\right)$ was observed for the bands due to both sulfonic and $\mathrm{C}-\mathrm{O}-\mathrm{C}$ groups with respect to reference values. No bands due to $\mathrm{Si}-\mathrm{O}-\mathrm{Si}$ bonds were observed [28]. Both the presence and the shift at higher frequencies of the

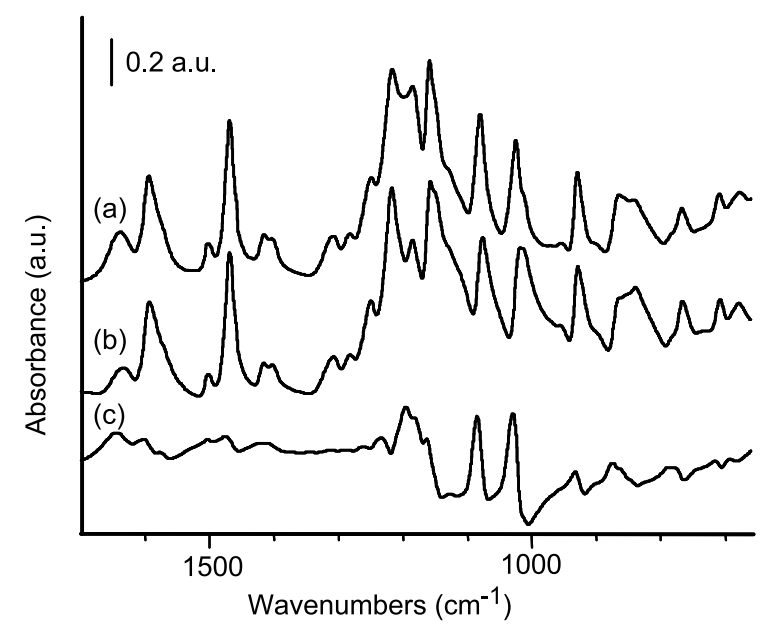

Fig. 2. ATR/FTIR spectra of (a) SiSPEEK, (b) SPEEK and (c) subtraction (a) $-1,00$ (b). bands observed indicate the formation of $\mathrm{C}-\mathrm{Si}$ bonds in two environments, in agreement with NMR results.

Thermogravimetric analysis was performed on SiSPEEK. Fig. 3 shows the relative TGA/DTG curves. Two weight loss steps were observed, reflected by two broad peaks in the DTG curve. The first weight loss (in the range $250-350{ }^{\circ} \mathrm{C}$, corresponding to a minimum at $275^{\circ} \mathrm{C}$ in the DTG curve) can be attributed to the decomposition of sulfonic acid groups, while the second weight loss (in the range $450-700{ }^{\circ} \mathrm{C}$ corresponding to a minimum at $540{ }^{\circ} \mathrm{C}$ in the DTG curve) is due to the pyrolysis of the polymer [29]. The thermogravimetric analysis showed no substantial difference with respect to the data relative to the parent SPEEK indicating that the formation of the hybrid did not alter the thermal stability of the polymeric structure.

Membranes of SiSPEEK were prepared by casting and activated in $5 \mathrm{M} \mathrm{H}_{2} \mathrm{SO}_{4}$ to transform the anionic form obtained from the synthesis into the acidic one. While SPEEK with elevated DS is reported to be soluble or form gel when immersed in water [29], SiSPEEK membranes deriving from SPEEK with $90 \%$ DS showed an elevated water uptake $(240 \%)$ still remaining flexible and easy to handle. The formation of covalently bound inorganic clusters increased then the level of water uptake, but did not result in excessive swelling or solubility in water of the membrane making conductivity measurements feasible.

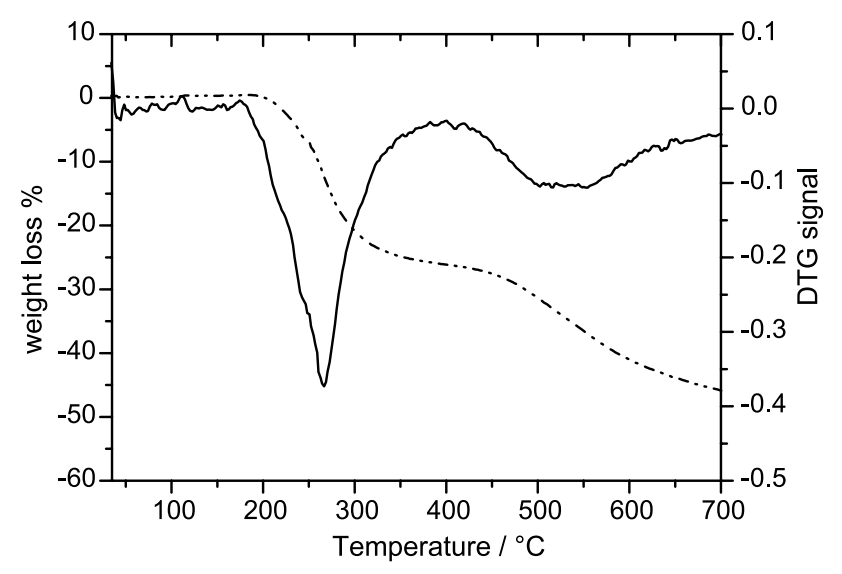

Fig. 3. TGA (dotted line) and DTG (solid line) curves of SiSPEEK. 
Ionic conductivity was measured at room temperature by electrochemical impedance spectroscopy (EIS) using blocking $\mathrm{Pt}$ electrodes in the frequency range $1 \mathrm{~Hz}-100 \mathrm{kHz}$. Stable conductivity values were measured over a week, in the range $2 \times 10^{-2}-1 \times 10^{-2} \mathrm{Scm}^{-1}$. No deviations from linearity were observed in the impedance spectra of all samples after different storage periods, therefore, implicating that the samples integrity is maintained over the examined period of time. Literature data for the room temperature conductivity of SPEEK membranes vary from $5.05 \times 10^{-3} \mathrm{~S} / \mathrm{cm}$ for $85 \%$ DS [3] to $8 \times 10^{-3} \mathrm{~S} / \mathrm{cm}$ for $80 \%$ DS [18]. The values obtained for SiSPEEK membranes show that while solubility properties are improved, conductivity values are not affected by the formation of the hybrid and values are suitable for performance as ion conducting membranes.

\section{Conclusions}

The first example of a proton conducting SPEEK-based hybrid membrane, where the inorganic component is covalently linked to the organic one, has been synthesized and characterized.

The formation of the hybrid materials made possible to prepare membranes with good thermal stability and enhanced water uptake capability, which resulted in good electrical characteristics.

Further improvement of the hybrid characteristics might be achieved adding a larger amount of inorganic functionalities with a better control of the extent of the inorganic network formation, which can be achieved using sol/gel processes. Studies on the development of such hybrid proton conducting polymers are currently in progress.

\section{Acknowledgements}

Thanks are due to Ms Cadia D'Ottavi for her valuable technical assistance and to Dr Marco Grotti (University of Genova) for performing Elemental Analysis. The financial support of MIUR (FISR) is acknowledged.

\section{References}

[1] Kreuer KD. J Membr Sci 2001;185:29-39.

[2] Bauer B, Jones DJ, Rozière J, Tchicaya L, Alberti G, Casciola M, et al. J New Mater Electrochem Syst 2000;3:93-8.
[3] Li L, Zhang J, Wang Y. J Membr Sci 2003;226:159-67.

[4] Zhang W, Tang C-M, Kerres J. Sep Purif Technol 2001;22-23: 209-21.

[5] Kerres J, Cui W, Junginger M. J Membr Sci 1998;139:227-41.

[6] Mikhailenko SD, Wang K, Kaliaguine S, Xing P, Robertson GP, Guiver MD. J Membr Sci 2004;233:93-9.

[7] Jörissen L, Gogel V, Kerres J, Garche J. J Power Sources 2002;105: 267-73.

[8] Sanchez C, De AA, Soler-Illia GJ, Ribot F, Grosso D. C R Chimie 2003;6:1131-51.

[9] Mikhailenko SD, Zaidi SM, Kaliaguine S. Catal Today 2001;67: 225-36.

[10] Bonnet B, Jones DJ, Rozière J, Tchicaya L, Alberti G, Casciola M, et al. J New Mater Electrochem Syst 2000;3:87-92.

[11] Alberti G, Casciola M. Annu Rev Mater Res 2003;33:129-54.

[12] Pourcelly G, Gavach C. In: Colomban P, editor. Proton conductors, solid, membranes, and gels-materials and devices. New York: Cambridge University Press; 1992.

[13] Houbertz R, Frohlich L, Poall M, Streppel U, Dannberg P, Brauer A, et al. Adv Eng Mater 2003;5:551-5.

[14] Ribeiro SJL, Messaddeq Y, Goncalves RR, Ferrari M, Montagna M, Aegerter MA. Appl Phys Lett 2000;77:3502-4.

[15] Haas KH, Rose K. Rev Adv Mater Sci 2003;5:47-52.

[16] Li Q, He R, Jensen JO, Bjerrum NJ. Chem Mater 2003;15:4896-915.

[17] Furniss BS, Hannaford AJ, Smith PWG, Tatchell AR. Textbook of practical organic chemistry. New York: Longman; 1989. p. 406.

[18] Zaidi SMJ, Mikhailenko MD, Robertson GP, Guiver MD, Kaliaguine S. J Membr Sci 2000;173:17-34.

[19] Hyperchem Release 5.11, Hypercube Inc.; 1999.

[20] Frisch MJ, Trucks GW, Schlegel HB, Scuseria GE, Robb MA, Cheeseman JR, Zakrzewski VG, Montgomery Jr JA, Stratmann RE, Burant JC, Dapprich S, Millam JM, Daniels AD, Kudin KN, Strain MC, Farkas O, Tomasi J, Barone V, Cossi M, Cammi R, Mennucci B, Pomelli C, Adamo C, Clifford S, Ochterski J, Petersson GA, Ayala PY, Cui Q, Morokuma KD, Malick K, Rabuck AD, Raghavachari K, Foresman JB, Cioslowski J, Ortiz JV, Baboul AG, Stefanov BB, Liu G, Liashenko A, Piskorz P, Komaromi I, Gomperts R, Martin RL, Fox DJ, Keith T, Al-Laham MA, Peng CY, Nanayakkara A, Gonzalez C, Challacombe M, Gill PMW, Johnson B, Chen W, Wong MW, Andres JL, Gonzalez C, Head-Gordon M, Replogle ES, Pople JA. Gaussian 98, Revision A.7; Gaussian, Inc.: Pittsburgh PA; 1998.

[21] West R, Jones PC. J Am Chem Soc 1986;90:2656-61.

[22] Yoshinaga H, Yamada N, Katayama S. J Sol-Gel Sci Technol 2003; 28:65-70.

[23] Kennedy JD, McFarlane W. In: Mason J, editor. Silicon, germanium, tin and lead-multinuclear NMR. New York: Plenum Press; 1987. p. 305-28.

[24] Brunetti T, Diddoro M, Di Vona ML, Floris B, Galloni P, Licoccia S. Eur J Org Chem 2004;521-6.

[25] Nguyen HX, Ishida H. Polym Prepr 1985;26:273-9.

[26] Nguyen HX, Ishida H. Polymer 1986;27:1400-11.

[27] Nguyen HX, Ishida H. J Polym Sci, Polym Phys Ed 1986;24:1079-90.

[28] Bellamy LJ. The infrared spectra of complex molecules. vol. 1. London: Chapman and Hall; 1980.

[29] Xing P, Robertson GP, Guiver MD, Mikhailenko SD, Wang K, Kaliaguine S. J Membr Sci 2004;229:85-106. 